\title{
Dynamic Calculation of Noise Barrier Subjected to Impulsive Wind Pressure Based on ANSYS
}

\author{
Wen-Jun LUO ${ }^{1, a}$ and Jun-Nan JIANG ${ }^{2, b}$ \\ ${ }^{1}$ East China Jiaotong University , Nanchang 330013 , China \\ ${ }^{2}$ East China Jiaotong University , Nanchang 330013 , China \\ a549761748@qq.com, b694989919@qq.com
}

Keywords: noise barrier of inserted, impulsive wind pressure, dynamic response

Abstract.According to the noise barrier structures of high-velocity railway,the structural character was systematically analyzed. In this paper, the simulation calculation method is adopted to analyze the impulsive wind pressure acted on the noise barrier of inserted based on ANSYS software.Different influence factors, which include the velocity of trains and distance between upright columns, are considered to simulate the transient dynamic response of the noise barrier structure. The variation trend of response by the influence of different factors is obtained. In addition, the optimal range for the distance between upright columns is put forward.

\section{Introduction}

With the rapid development of railway construction in our country, traffic service becomes convenient, however, noise pollution along the railway line is increasingly serious at the same time. The noise barrier set up on both sides of railway lines is one of the main measures to reduce noise pollution, and it has been obviously used at home and abroad. At present, metallic noise barrier of inserted is mainstream in China and widely employed in the railway construction, this type in the total number of noise barrier accounted for more than $90 \%$. Due to the increase of velocity of train, the influence of noise barrier structure caused by the impulsive wind pressure becomes more significant, only static loading analysis can not meet the practical requirements. In order to ensure the safety of the structure, the analysis of simulating the dynamic response for noise barrier structure subjected to impulsive wind pressure is necessary .

\section{Pressure calculation}

Pressure on the noise barrier structure include gravity, wind pressure and the impulsive wind pressure, which is caused by severe disturbance of the air nearby when high-velocity train passes by, the alternating positive and negative pressure wave are caused by the disturbance on the surface of noise barrier in the short time. Pressure wave increases obviously with the increase of train velocity. Therefore, the influence of impulsive wind pressure on noise barrier structure should be focused on , when the train run with the high velocity at approximately $350 \mathrm{~km} / \mathrm{h}$. Researchers in Germany have made related online road test before, the German railway company have presented the curve for ICE3 (high-velocity train). Based on FE dynamic analysis, the impulsive wind pressure on the noise barrier can be expressed as Eq. 1.

$$
q=c_{p} \cdot c_{z} \cdot \rho \cdot \frac{v^{2}}{2}
$$

Where $q$ is the impulsive wind pressure $\left(N / m^{2}\right), c_{P}$ is the coefficient of impulsive wind pressure, ${ }^{c_{z}}$ is the coefficient the height above the rail surface, $\rho$ is the air density $\left(\mathrm{kg} / \mathrm{m}^{3}\right), v_{\text {is }}$ 
the train velocity $(\mathrm{m} / \mathrm{s})$.

\section{FE model for noise barrier}

In this paper, FE model for metallic noise barrier of inserted is established. According to the standard of noise barrier for railway engineering construction, metallic noise barrier of inserted includes H-Beam upright column, H-Beam baseplate, aluminum alloy elemental plate, rubber and so on. The size and the connection are shown in Fig 1.

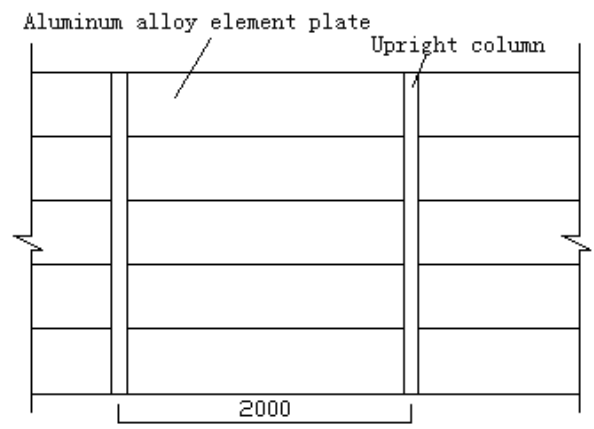

Fig 1. Size and Connection

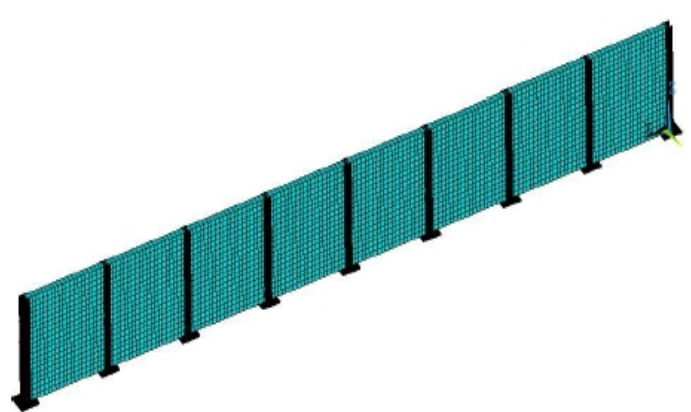

Fig 2. FE Model for Noise Barrier of Inserted

In order to analyze the dynamic response of noise barrier structures subjected to impulsive wind pressure, FE model is established for metallic noise barrier, which is $16 \mathrm{~m}$ in length(8-span) and $2.15 \mathrm{~m}$ in height. While solid45 entity unit is simulated for H-Beam upright column(HW $175 \times 175)$, shell 63 entity unit is simulated for aluminum alloy elemental plate $(1950 \times 430 \times 140)$, the monotube rubber blanket between upright column and elemental plate is simulated by solid45 entity unit, which is connected to upright column by common node and connected to elemental plate by coupling constraint. Meanwhile, snap-fit connection is simulated for the connection of elemental plates. Bulge and groove are ignored, and damping factor is simulated for rubber. In addition, in order to show the modes of vibrations of aluminum alloy elemental plates better, the materials in noise barrier structures are ignored because of the little density of sound-insulation materials. FE model for noise barrier of inserted is shown in Fig 2 and parameters are given in Table 1.

Table 1. Parameters for Noise Barrier Structure

\begin{tabular}{|c|c|c|c|c|c|c|}
\hline $\begin{array}{l}\text { Name of } \\
\text { component }\end{array}$ & $\begin{array}{l}\text { Type of } \\
\text { element }\end{array}$ & Material & Density & $\begin{array}{l}\text { Modulus } \\
\text { of } \\
\text { elasticity }\end{array}$ & $\begin{array}{l}\text { Poisson } \\
\text { ratio }\end{array}$ & Damping \\
\hline $\begin{array}{l}\text { H-Beam upright } \\
\text { column }\end{array}$ & SOLID45 & $\begin{array}{l}\text { Carbon } \\
\text { steel }\end{array}$ & 7800 & $2.00 \mathrm{E}+05$ & 0.274 & 0.002 \\
\hline Elemental plate & SHELL63 & $\begin{array}{l}\text { Aluminum } \\
\text { alloy }\end{array}$ & 2700 & $7.00 \mathrm{E}+04$ & 0.3 & $1.00 \mathrm{E}-05$ \\
\hline Rubber & SOLID45 & Rubber & 1230 & 3 & 0.32 & 0.1 \\
\hline
\end{tabular}

\section{Analysis on transient dynamic response}

\section{Influence of train velocity}

Upright columns should be analyzed,because upright columns are the weakest in the whole noise barrier of inserted structure. The dynamic response curve along the length of the noise barrier 
structure caused by CRH2 passing by is shown in Fig 3, as shown, the distribution of maximum displacement and maximum stress between upright columns are nearly the same, both of two first increase, then decrease and then increase along the length, until the last upright column would reach to maximum, the maximum displacement and the maximum stress of the penultimate and the last upright column vary remarkable. The maximum dynamic response of noise barrier structure subjected to impulsive wind pressure appears at the last upright column.

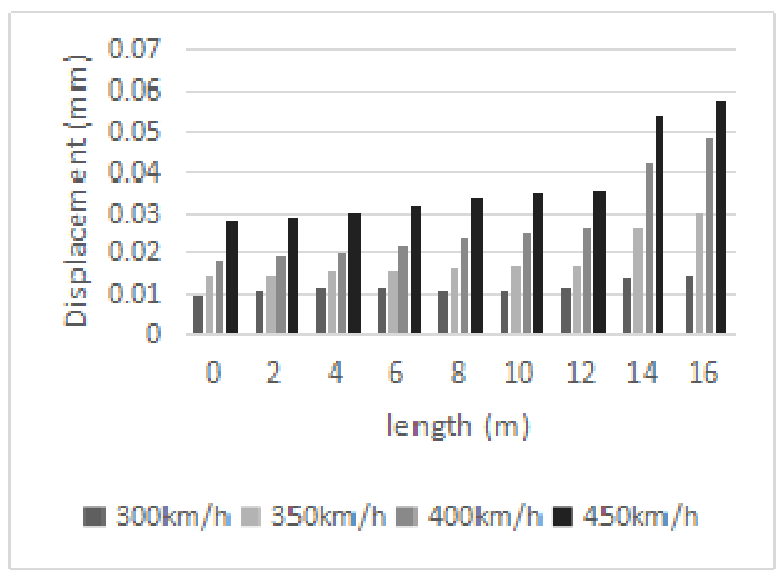

(a)Maximum Displacement

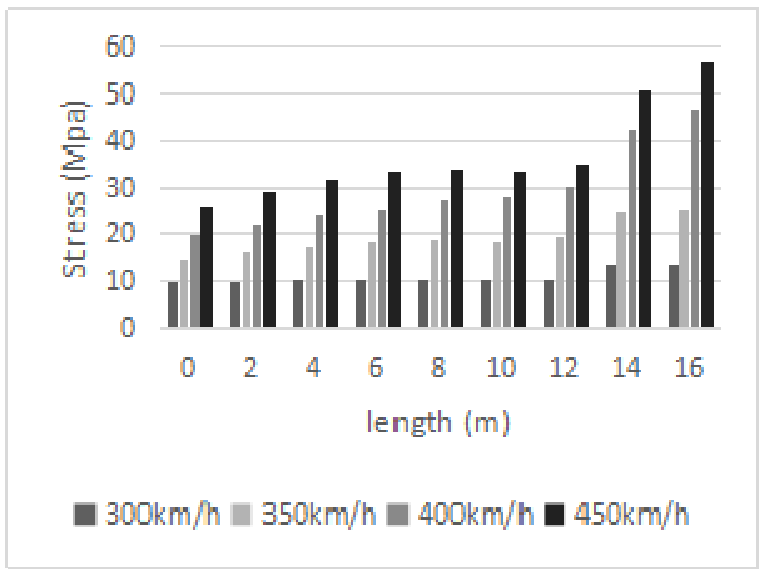

( b)Maximum Stress

Fig 3. Maximum Displacement and Maximum Stress between Upright Columns in Different Location

Maximum displacement and maximum stress between upright columns of the whole noise barrier structure caused by the train passing by at the velocity of $300 \mathrm{~km} / \mathrm{h} 、 350 \mathrm{~km} / \mathrm{h} 、 400 \mathrm{~km} / \mathrm{h} 、 450 \mathrm{~km} / \mathrm{h}$ is given in Table 2. The maximum displacement is $0.0132 \mathrm{~m}$ and the maximum stress is $13.8 \mathrm{Mpa}$ at the velocity of $300 \mathrm{~km} / \mathrm{h}$. as shown, the displacement and stress increase obviously with a nonlinear relationship with the increases of velocity of trains and distance of upright column.

Table 2. Maximum Displacement and Maximum Stress between Upright Columns

\begin{tabular}{lllll}
\hline Velocity (km/h) & 300 & 350 & 400 & 450 \\
\hline Maximum displacement (m) & 0.0132 & 0.0292 & 0.0484 & 0.0581 \\
\hline Maximum stress ( Mpa) & 13.8 & 30 & 47.2 & 57.3 \\
\hline
\end{tabular}

\section{Influence of the distance between upright columns}

In order to study the influence of the distance between upright columns on dynamic response of noise barrier of inserted, the dynamic response at the distance of $1 \mathrm{~m}, 1.6 \mathrm{~m}, 2 \mathrm{~m}, 3.2 \mathrm{~m}$ is analyzed. According to Equations 1, caused by the train passing by at the velocity of $300 \mathrm{~km} / \mathrm{h}$, impulsive wind pressure curve of $16 \mathrm{~m}$ long noise barrier structure of 5-span, 8-span, 10-span and 16-span is calculated.

As shown in Fig 3, according to the analysis of the relationship between the response of upright column and the velocity of train in different location, both maximum displacement and maximum stress appear at the last upright column,which is the most unsteady. So this upright column(the last upright column) is chosen to analyze the influence of the distance between upright columns on dynamic response of noise barrier structure. The displacement and stress curve at the distance of $1 \mathrm{~m}$ and $2 \mathrm{~m}$ is shown in Fig 4. 


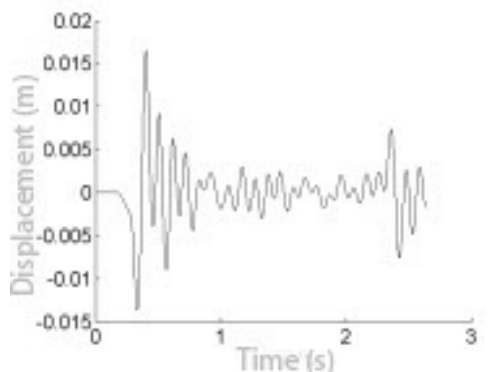

(a)Time Curve of Displacement at Distance of $1 \mathrm{~m}$

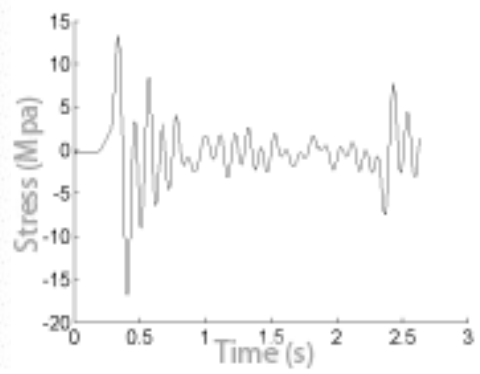

(b) Time Curve of Stress at Distance of $1 \mathrm{~m}$ at Distance of $1 \mathrm{~m}$

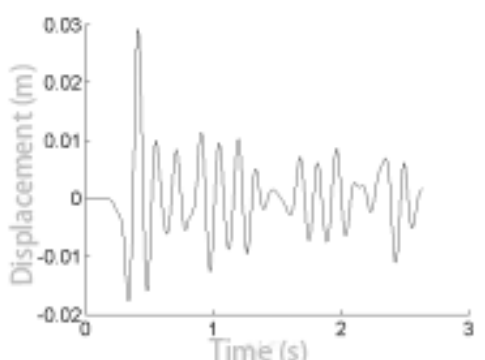

(c) Time Curve of Displacement at Distance of $2 \mathrm{~m}$

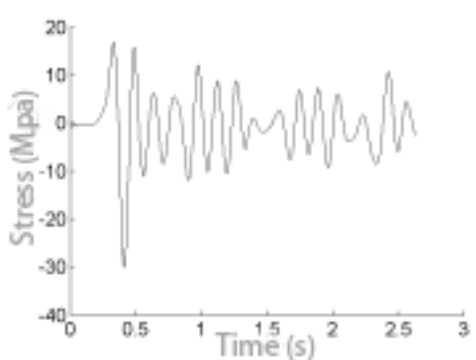

(d) Time Curve of Stress at Distance of $1 \mathrm{~m}$ at Distance of $2 \mathrm{~m}$

Fig 4. Time Curve of Displacement and Stress for Upright Columns at Different Distance

As shown in Fig 4,the variation of time curve of displacement, stress and impulsive wind pressure of the last upright column are nearly the same, the maximum value of response is caused by head wave, the minimum value is caused by intermediate wave, and the moderate value is caused by coda wave. The response caused by intermediate wave increases obviously with the increase of the distance between upright columns. When the distance between upright columns is 2 meters, the value of the response rise to peak several times, it has bad influence on the fatigue life of H-Beam upright column.

Table 3. Maximum Displacement and Maximum Stress at Different Distance between Upright Columns

\begin{tabular}{|c|c|c|c|c|}
\hline Distance $(\mathrm{m})$ & & 1.6 & 2 & 3.2 \\
\hline $\begin{array}{l}\text { Maximum } \\
\text { displacement } \\
(\mathrm{m})\end{array}$ & 0.0165 & 0.0239 & 0.0292 & 0.0374 \\
\hline $\begin{array}{l}\text { Maximum } \\
\text { stress } \\
(\mathrm{Mpa})\end{array}$ & 16.9 & 25.1 & 30 & 35.1 \\
\hline
\end{tabular}

Considering the distance between upright columns, at the distance of $1 \mathrm{~m}, 1.6 \mathrm{~m}, 2 \mathrm{~m}$ and $3.2 \mathrm{~m}$, the maximum displacement and the maximum stress of the last upright column is given in Table 3 . The maximum displacement is $0.0165 \mathrm{~m}$ and the maximum stress is $16.9 \mathrm{Mpa}$ at the distance of $1 \mathrm{~m}$, as shown, the displacement and stress of the last upright column increase with a nonlinear relationship with the increases of the distance between upright columns.

\section{Conclusions}

Both maximum displacement and maximum stress of upright columns, first increase, then decrease and then increase along the length, until the last upright column would reach to maximum, the 
maximum displacement and the maximum stress of the penultimate and the last upright column vary remarkable.Therefore, great attention should be paid to strengthen the noise barrier structure at the last upright columns and their adjacent upright columns.

Maximum displacement and maximum stress of all the upright columns increase with the increase of the velocity of train and the distance between upright columns, in nonlinear relation. Meanwhile, The response caused by intermediate wave increases obviously with the increase of the distance between upright columns, appearing several peak value, which has bad influence on the stability of the structure.

\section{Acknowledgements}

This research is partly supported by National Natural Science Foundation (51468021), Jiangxi Province Natural Science Foundation(20161BAB206160), and Jiangxi Province Yuanhang Engineer Foundation

\section{References}

[1]Zhong,Z.Q., Bai, Z.Y., \& Peng,X.C.Domestic and foreign research progress of rail traffic noise barrier[J].Guangdong Chemical Industry.2012 , 39(8):118-120.

[2]Wu,H.Y. Advances on insertion loss theory of road barrier[J].Noise and Vibration Control.2006, 3:85-88.

[3]Zhou,X.,Xiao,X.B., \& He,B. Numerical model for predicting the noise reduction of noise barrier of of high speed railway and its test validation[J]. Journal of Mechanical Engineering. 2013 , 49(10):14-19.

[4]Luo,K., \& Lei,X.Y.Analysis of the influence factors of railway sound barrier on noise reduction influence influence[J].Noise and Vibration Control.2008 , 5:142-146.

[5]Gu,X.A.,Li,Y.Z.,Liu,L.J., \& Li,Y.L.Application and effect of high-speed railway noise barrier in China[J].Railway Transport and Economy.2012 , 34(9):54-58.

[6]Long ,L.P. , Zhao,L.B., \& LIU, Li.D.Research on the air turbulent force pressureen on noise barrier caused by train[J].Engineering Mechanics.2010 , 27(3):246-250.

[7] Matthias Scholz, Zichard Buba , Mueller Boruttau Consulting Report:Noise barrier for high velocity railway[R].China , Beijing:Germany Planning Engineering Consulting Services Ltd , 2007.

[8]Lv,J.P.Structural study on the noise barrier of inserted and integral type for high-velocity railway[D].Nanjing:Southeast University.2010.

[9]Han,J.Q.Noise barrier performance of high--velocity track and primary investigation of its reducing pressure techniques[D].Chengdu:Southeast Jiaotong University.2014

[10]Jiao,C.Z., Gao,B., \& Wang,G.D.Vibration analysis of noise barrier structures subjected to train-Induced impulsive wind pressure[J].Journal of Southeast Jiaotong University.2007 , 42(5):531-536. 